\title{
Microwave Apparatus for Kinetic Studies and in-situ Observations in Hydrothermal or High-Pressure Ionic Liquid System
}

\author{
Masaru Watanabe, Xinhua Qi, Taku M. Aida and Richard Lee Smith, Jr.
}

Additional information is available at the end of the chapter

http://dx.doi.org/10.5772/45625

\section{Introduction}

\subsection{Microwave heating on organic reactions}

As many noticeable studies are introduced in this book, microwave heating technique has gained high expectation for utilizing various chemical processes including material synthesis, organic synthesis and conversion of energy resource with high reaction and energy efficiency. For organic synthesis, Gedye et al. ${ }^{[1]}$ and Giguere et al. ${ }^{[2]}$ prove effectiveness of microwave heating to accelerate organic reactions. Comparison of the energy efficiency between a conventional oil bath synthesis and a microwave-assisted synthesis has indicated that a significant energy savings of up to 85 -fold can be expected using microwaves as an energy source on a laboratory scale ${ }^{[3]}$. It was also shown that microwave heating on organic chemical reaction had much higher yields within short reaction times for some products ${ }^{[4]}$. These high efficiency would be kept for a pilot scale plant and the plant must be greener chemical process because of pre-workup reduction and associated energy savings.

\subsection{Importance of kinetic data and in-situ observation}

To develop an industrial process for a new chemical reaction, one has to grasp a correct kinetics of the reaction as a fundamental data to design a reactor and set an operating condition. Kinetic data can be measured using either batch reactor, semi batch reactor and flow reactor. However, the important points to evaluate kinetics are to keep operating condition constant and to know reaction time correctly. Particularly, it is quite difficult for a batch and a semi-batch reactor to be achieved to a desired temperature rapidly and/or cooled down to enough low temperature spontaneously. 
Furthermore, chemical reaction is affected with mass transfer occurring at phase boundary. Ionic liquid, which is widely investigated as reaction media for biomass conversion, is high viscous liquid depending on a solute concentration, amount of additive and temperature and a reaction in it is sometimes controlled by flow dynamics in a reactor. To know the effect of mass transfer on reaction kinetics, in-situ observation often provides a meaningful hint.

\subsection{Concept for development of a new microwave heating apparatus}

Advantage of microwave irradiation is capable of rapid heating via absorption of a heated target, mainly dielectric substance like water, carbon, some kinds of metal oxides, and so on. Now we consider microwave irradiation for high pressure vessel containing water. That is, to keep liquid phase of water over $100{ }^{\circ} \mathrm{C}$, a pressure vessel has to be used to resist higher pressure than atmospheric one. In the high pressure vessel for microwave irradiation, rapid cool down is typically impossible due to lower heat transfer of a material (ceramics and plastics are used in a commercial set up) for the high pressure vessel. To cool down rapidly using air blow, which is a simple way for cooling, a metal material is favorable owing to its high heat conductivity (heat conductivity of stainless steel is around 20). But a metal material reflects microwave and it is not heated up by microwave irradiation. On the other hand, a microwave-transparent material has low heat conductivity (heat conductivity of ceramics is single digit and that of plastics is one digit smaller than ceramics) and rapid cooling by air blow can not be expected. In addition, high pressure vessel for microwave irradiation is composed of visible light-proof materials (which does not allow visible light pass through), for example, alumina, Teflon, and so on, and in-situ observation of reaction behavior in the vessel is basically impossible. To overcome these disadvantages, we developed a novel high-pressure reactor for microwave irradiation, which is capable of rapid heating, rapid cooling and in-situ observation. The key points of the reaction vessel are three as follows: (1) a commercial Pyrex glass cup and polycarbonate (PC) tube, of which transparency for visible light are quite high, are employed to compose the vessel as inner and outer tube, respectively, (2) heat insulating space between the inner glass and outer PC tube allow a reaction fluid in the glass cup to be heated up to $200{ }^{\circ} \mathrm{C}(\mathrm{PC}$ is engineering plastics, however its heat tolerance is low and PC can normally be used up to $100{ }^{\circ} \mathrm{C}$ ), and (3) the heat insulating space can be used for cooling unit after the reaction by introducing cooling water. The detail of the microwave setup and a typical procedure are describe below.

\section{Microwave apparatus}

\subsection{Setup of microwave apparatus}

Figure 1 shows a schematic diagram of the microwave apparatus. Figures 2 and 3 show cover shot of the setup and photograph of high pressure vessel $(2 \sim 6$ in Figure 1$)$, respectively. The setup consists of a multimode microwave generator (1) $\mu$-Reactor, SMW087, 2.45 GHz, maximum power 700 W, Shikoku Keisoku, Takamtsu, Japan) with a K-type thermocouple (2), a stirring system (5 and 15), a control box (16:, a high pressure reactor 
(consists of 3, 4, 6 and 7), a pressure gauge (8), an inert gas (Ar or $\mathrm{N}_{2}$ ) cylinder (13), a cooling water tank (18) and a vacuum pump (14). The reactor was composed of an inner thick-wall Pyrex glass tube (4: HPG-10, volume $10 \mathrm{ml}$, maximum supporting pressure $10 \mathrm{MPa}$, TaiatsuTechno. Corporation, Tokyo, Japan), an outer PC tube (3) and two PEEK (Teflon or $\mathrm{PC}$ is OK depending on operating temperature) screw caps (6 and 7) with special seal joint (consists of stainless steel connectors, Teflon O-ring, and Viton O-ring) used to fix glass tube and PC tube. The thermocouple (2) is inserted into the glass reactor (4) through a stainless steel sleeve and fixed with the inner wall of microwave oven to avoid microwave leakage from the oven (for this reason, an aluminum plate is also placed on a hole opened at the top of the microwave oven) and sparks produced from the thermocouple. Sparks from the thermocouple have never observed during all the experiments. The leakage of microwave was monitored by a microwave survey meter (Holiday Industries Inc., Model HI-1501) for safety and found to be less than $1 \mathrm{~mW} / \mathrm{cm}^{2}$ at distance of $5 \mathrm{~cm}$ far away from the microwave oven. The temperature inside the reactor is monitored and controlled by the control box (16). The temperature and power of microwave were monitored and recorded using a computer (21).

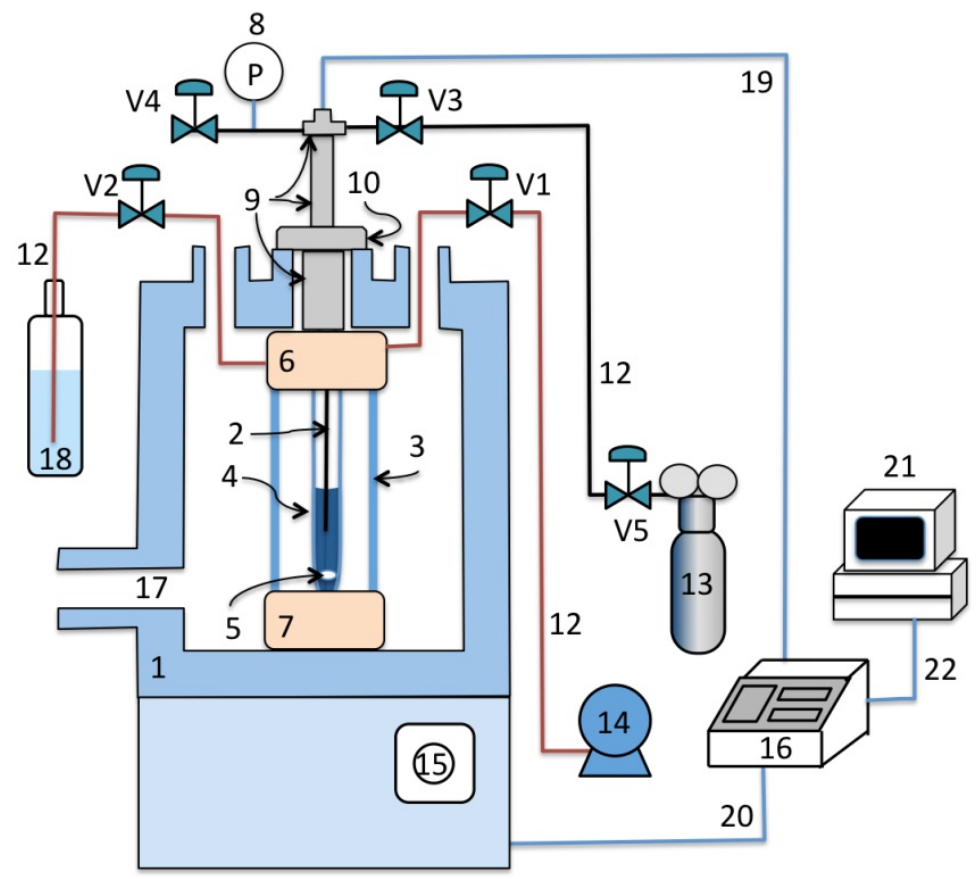

1- Microwave oven, 2- K-type Thermocouple 3- Polycarbonate outer tube, 4- Thick-walled glass reactor, 5- Stirrer bar, 6- PEEK, Tefron, or PC cap, 7- PEEK, Tefron, or PC bottom, 8- Pressure indicator, 9- Stainless steel connectors, 10Aluminum plate, 11- PEEK line, 12- Stainless steel line, 13- inert gas (Ar or N2) cylinder, 14- Vacuum pump, 15- Stirrer controller, 16- Power controller, 17- Observation window, 18- Cooling water tank, 19- Thermocouple connecting line, 20-Controller connecting line, 21- Computer, 22- Computer connecting line, V1 V5- stop valves

Figure 1. Microwave heating experimental setup 


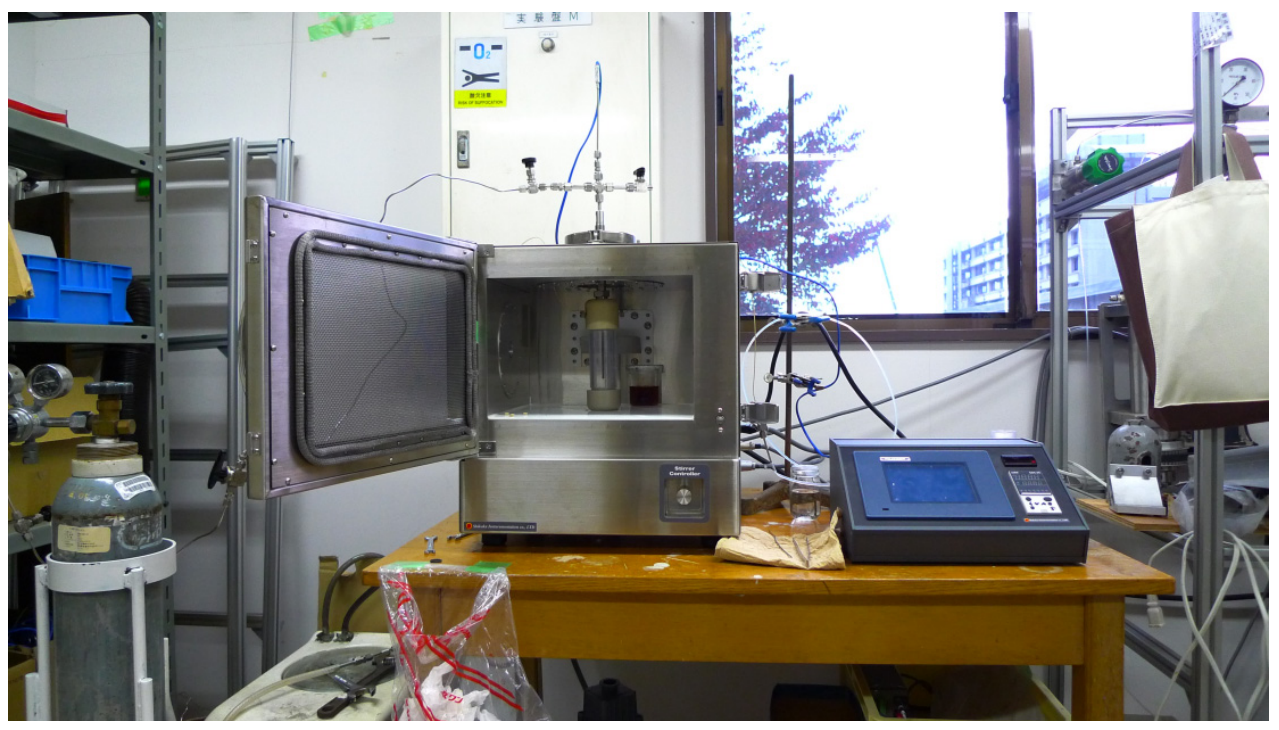

Figure 2. Cover shot of microwave heating experimental setup

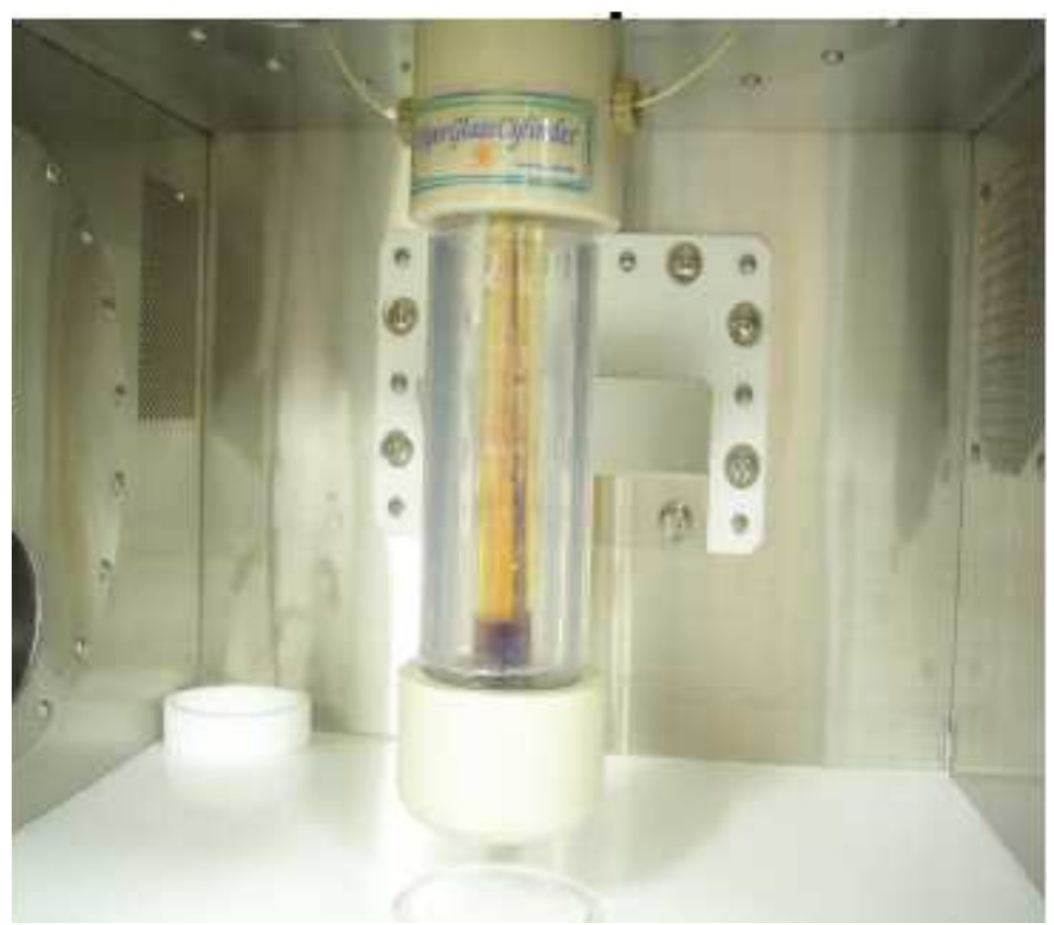

Figure 3. Photograph of high pressure vessel 


\subsection{Typical procedures for microwave heating experiments}

A typical workup procedure for an experiment is as follows: An sample solution which must contain dielectric substance (water, polar solvents, ionic liquids, carbon, some kinds of metal oxides, etc) and sometimes a given amount of a catalyst are loaded into the glass tube (4) with a stirrer bar (5). The glass tube (4) is mounted into a PC tube (3) that is closed with PEEK screw caps (6 and 7: Teflon and PC caps are sometimes used depending on reaction temperature). This assembly is placed into the microwave oven (1) as shown in Figure 1. An inert gas (such as $\mathrm{Ar}$ and $\mathrm{N}_{2}$ ) is used for purging air inside the reactor at a pressure of about 1.2 MPa. Then a vacuum pump (14) evacuates air from the space between the inner glass tube (4) and the outer PC tube (3) to minimize conductive heat losses. Introduction of cooling water into this vacuum space provided a method for rapidly cooling of the reactor. When microwave irradiation is started, the reaction mixture could be heated up to $200{ }^{\circ} \mathrm{C}$ within $60 \mathrm{~s}$ depending on the kind and amount of materials and substrates. Figure 4 shows a temperature and power of microwave profile at the experiments of fructose conversion in water in the presence of $\mathrm{TiO}_{2}$ at $200{ }^{\circ} \mathrm{C}$ for $2 \mathrm{~min} 30 \mathrm{~s}$. In this experiment, the reaction fluid was rapidly heated up to $200{ }^{\circ} \mathrm{C}$ for $30 \mathrm{~s}$. After a desired reaction time passed, microwave irradiation was turned off, stop valve (V1) located at the line between the PC cap (6) and the vacuum pump (14) is closed, the vacuum pump (14) is stopped. After that, stop valve (V2) connected the line between the PC cap (6) and the cooling water tank (18) is opened to admit introduction of cooling water from tank (18) into the PC tube. By the cooling process, the reaction solution could rapidly be cooled down to below $80{ }^{\circ} \mathrm{C}$ within $60 \mathrm{~s}$. As shown in Figure 4 , at the fructose conversion experiment in water, the solution in the reaction vessel was rapidly cooled down to $80^{\circ} \mathrm{C}$ within $30 \mathrm{~s}$. After cooling, stop valve (V4) at the opposite site of the inert gas cylinder is opened and the inert gas inside the glass tube (4) is discharged. The reactor is disassembled and the reaction solution is collected by washing

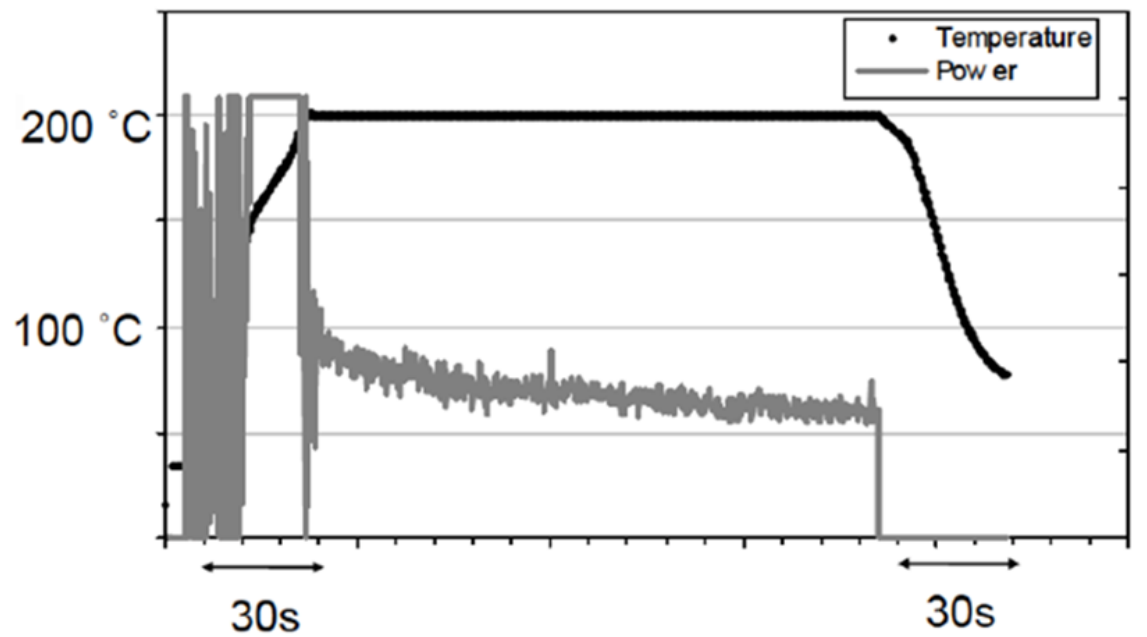

Reaction condition: $5 \mathrm{~mL}$ fructose aqueous solution, $0.05 \mathrm{~g} \mathrm{TiO}_{2}$, set temperature $200{ }^{\circ} \mathrm{C}$, maximum power $700 \mathrm{~W}$

Figure 4. Temperature and power profile during a reaction 
the glass tube (4) with an amount of an appropriate solvent. During a reaction, reaction behavior can be observed from a observation window (17) and we sometimes record the images of some experiments with a digital video camera. One example is shown in the section of ionic liquid system concerning cellulose hydrolysis in an ionic liquid.

\section{Experimental results and discussion}

\subsection{Topics described in this chapter}

Special feature of microwave for improving reaction was noticed in organic synthesis for the first time. There have been many papers on microwave-assisted organic synthesis ${ }^{[1,5-9]}$ and only a limited number of studies have been reported about biomass conversion into a chemical block ${ }^{[10-13]}$. Here, we introduce four experimental results of biomass conversion in hydrothermal condition and ionic liquid systems. At first, fructose conversions into 5hydroxylmethyl furfural (HMF), which is an important chemical block, in the presence of catalysts at hydrothermal condition ${ }^{[14]}$ or in water mixture ${ }^{[15]}$ are introduced. Second, we described partial oxidation of glycerol into formic acid with hydrogen peroxide at hydrothermal condition ${ }^{[16]}$. Both the hydrothermal reactions are described in the next section. The third topic is glucose transformation into HMF in an ionic liquid. We compared kinetics and product distribution of these reactions by microwave heating with those by a heating bath (outer heating such as a fluidized sand bath, a molten salt bath and an oil bath, which are capable of rapid heating as same heating rate as microwave heating). Finally, we demonstrated usefulness of $i n$-situ observation of cellulose hydrolysis in high pressure ionic liquid-water mixture for considering importance of mass transfer (or phase separation) on the hydrolysis.

\subsection{Experimental by outer heating}

For the experiments using the outer heating, procedures for loading and recovering the samples were basically the same as those used in the microwave heating experiments, as explained in the previous section. Reactions were conducted with stainless steel 316 tube bomb reactors (inner volume: $6 \mathrm{~mL}$ ). A given amount of solution (sample and solvent), catalyst (anatase $\mathrm{TiO}_{2}$ for the fructose conversion at hydrothermal condition, Dowex 50wx8100 ion-exchange resin for that in water-acetone mixture, $\mathrm{CrCl}_{3}$ for glucose conversion in ionic liquid system), and/or additive (hydrogen peroxide for glycerol partial oxidation) were loaded into the reactor. Then, purging air inside the reactor was done by an inert gas (Ar or $\mathrm{N}_{2}$ ) and the gas was fed in the reactor at 1.2 $\mathrm{MPa}$ of pressure. After the loading, the reactor was submerged into a heating bath and heated up to targeted temperature. The heating rate of the outer heating was as the same as the microwave heating (within $90 \mathrm{~s}$ for either heating bathes employed in this study). Here, sands fluidized in the fluidizing sand bath are fused alumina particles and the salt in the molten salt bath is $50 \mathrm{wt} \% \mathrm{KNO}_{3}-50 \mathrm{wt} \% \mathrm{NaNO}_{3}$ salt mixture. Silicone oil was used for an oil bath used in the study on glucose conversion in an ionic liquid. After the reaction time was passed, the reactor was taken out of the bath and quenched in a water bath that was at room temperature. The cooling rate in the water bath of the stainless steel reactor was also the same as that by the cooling system in the 
microwave setup. Before opening the reactor, the gas in the reactor was released. Even for the partial oxidation experiments, gas analysis was not conducted. The liquid samples in the reactor were collected with rinsing of the reactor with water. The solid in the recovered solution, namely anatase $\mathrm{TiO}_{2}$ or Dowex $50 \mathrm{w} x 8-100$ for the fructose reaction, was separated from the liquid sample by filtration before analysis. No solid was obtained at the partial oxidation of glycerol and the HMF formation from glucose

\subsection{Fructose conversion into HMF at hydrothermal condition ${ }^{[14]}$}

Firstly, the effect of microwave heating on the fructose conversion in hydrothermal condition $^{[15]}$ was mentioned. The experimental results are listed in Table 1 and parity plot of these values are plotted in Figure 5. The major products obtained by both the outer heating and the microwave heating, were glucose, HMF, furfural and organic acids (lactic acid, hydroxyacetone, formic acid, acetic acid and levulinic acid). The product yields for the experiments by microwave heating were totally higher than those by the outer heating. Especially, the most dominating product, $\mathrm{HMF}$, was obtained much more for the microwave heating than for the outer heating. As shown in Table 1, for 3 min reaction time, the fructose conversion and HMF yields for the outer heating bath were $35 \mathrm{~mol} \%$ and $12 \mathrm{~mol} \%$, respectively, while the corresponding values for the microwave heating were $73 \mathrm{~mol} \%$ and $27 \mathrm{~mol} \%$, respectively. For $5 \mathrm{~min}$ of the reaction, the fructose conversion ( $65 \mathrm{mo} \%$ by the outer heating and $84 \mathrm{~mol} \%$ by the microwave heating) and the HMF yield (27 $\mathrm{mo} \%$ by the outer heating and $34 \mathrm{~mol} \%$ by the microwave heating) were also enhanced. Both fructose conversions and HMF yields were enhanced with microwave heating compared with the outer heating, while the HMF selectivities obtained by the outer heating ( $34 \%$ for $3 \mathrm{~min}$ and $41 \%$ for $5 \mathrm{~min}$ ) was almost the same as those by the microwave heating ( $38 \%$ for $3 \mathrm{~min}$ and $40 \%$ for $5 \mathrm{~min}$ ). The parity plots of the reactions in the outer heating and the microwave heating clearly show the differences. Figure 5 apparently indicates that the microwave heating enhanced the total conversion of fructose but the reaction of fructose into HMF was not strongly affected by the heating method. It was well known that HMF was formed via dehydration from fructose and further reacted with water to form levulinic acid. At an early stage of the fructose reaction (namely shorter reaction time), HMF formation was dominantly occurred but the produced HMF was degraded into the other products at a latter stage of the reaction. As indicated in Table 1 and Figure 5, the HMF selectivity at the microwave heating for $3 \mathrm{~min}$ was a little higher than that at the outer heating. This probably indicated that the reaction pathway of HMF formation was slightly promoted by the microwave heating.

\begin{tabular}{|c|c|c|c|c|}
\hline & Time, min & $\begin{array}{c}\text { Fructose } \\
\text { conversion, } \mathrm{mol} \%\end{array}$ & HMF yield, mol \% & HMF selectivity, $\%$ \\
\hline \multirow[t]{2}{*}{ Outer heating } & 3 & 35.3 & 12.1 & 34.3 \\
\hline & 5 & 65.3 & 26.9 & 41.2 \\
\hline \multirow{2}{*}{ Microwave heating } & 3 & 73.1 & 27.9 & 38.2 \\
\hline & 5 & 84.1 & 33.5 & 39.8 \\
\hline
\end{tabular}

Condition: $5 \mathrm{~mL}$ of $2 \mathrm{wt} \%$ of fructose, $0.2 \mathrm{~g}$ of anatase $\mathrm{TiO}_{2}, 200{ }^{\circ} \mathrm{C}$ of reaction time

Table 1. Comparison of fructose conversion between the outer heating and microwave heating[15] 


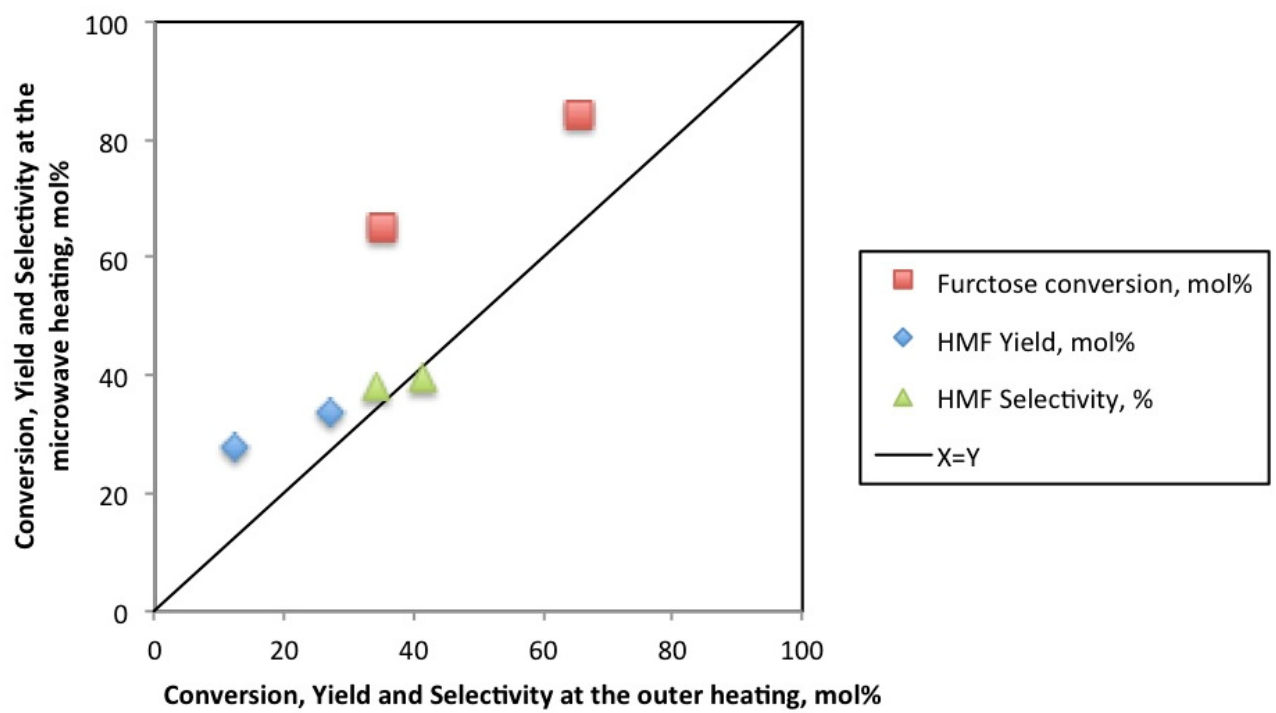

Figure 5. Parity plot of the fructose conversion at hydrothermal condition: comparison of fructose conversion, HMF yield and HMF selectivity between the outer heating and the microwave heating

\subsection{Fructose conversion into HMF in acetone-water mixture ${ }^{[15]}$}

The dehydration of D-fructose (2 $\mathrm{wt} \%)$ in an acetone-water mixture $(70: 30, \mathrm{w} / \mathrm{w})$ with an ion-exchange resin as catalyst by convective heating (sand bath) and microwave irradiation heating was also studied at $150{ }^{\circ} \mathrm{C}$ with keeping liquid phase by giving over the vapor pressure (Table 2 and Figure 6). Figure 6 is also parity plot as well as Figure 5. That is, when a plot in the graph is higher than $\mathrm{X}=\mathrm{Y}$ line, the phenomenon is favored to be occurred by the microwave heating. As shown in Figure 6, microwave irradiation was significantly more efficient not only for fructose conversion but also for 5-HMF yields. In addition, the selectivity of HMF formation by the microwave heating was slightly higher that by the outer heating.

\begin{tabular}{ccccc}
\hline & $\begin{array}{c}\text { Reaction time, } \\
\min \end{array}$ & $\begin{array}{c}\text { Fructose conversion, } \\
\mathrm{mol} \%\end{array}$ & $\begin{array}{c}\text { HMF Yield, } \\
\mathrm{mol} \%\end{array}$ & $\begin{array}{c}\text { HMF Selectivity, } \\
\%\end{array}$ \\
\hline Outer heating & 5 & 7.8 & 5.7 & 73.1 \\
& 10 & 22.1 & 13.9 & 62.9 \\
\hline $\begin{array}{c}\text { Microwave } \\
\text { heating }\end{array}$ & 5 & 64.5 & 54.0 & 83.7 \\
& 10 & 91.7 & 70.3 & 76.7 \\
\hline
\end{tabular}

Condition: acetone:water $=70: 30 \mathrm{w} / \mathrm{w}, 5 \mathrm{~mL}$ of $2 \mathrm{wt} \%$ fructose solution, $0.1 \mathrm{~g}$ Dowex $50 \mathrm{wx} 8-100,150^{\circ} \mathrm{C}$ of reaction temperature

Table 2. Comparison of fructose conversion between the outer heating and microwave heating ${ }^{[16]}$ 


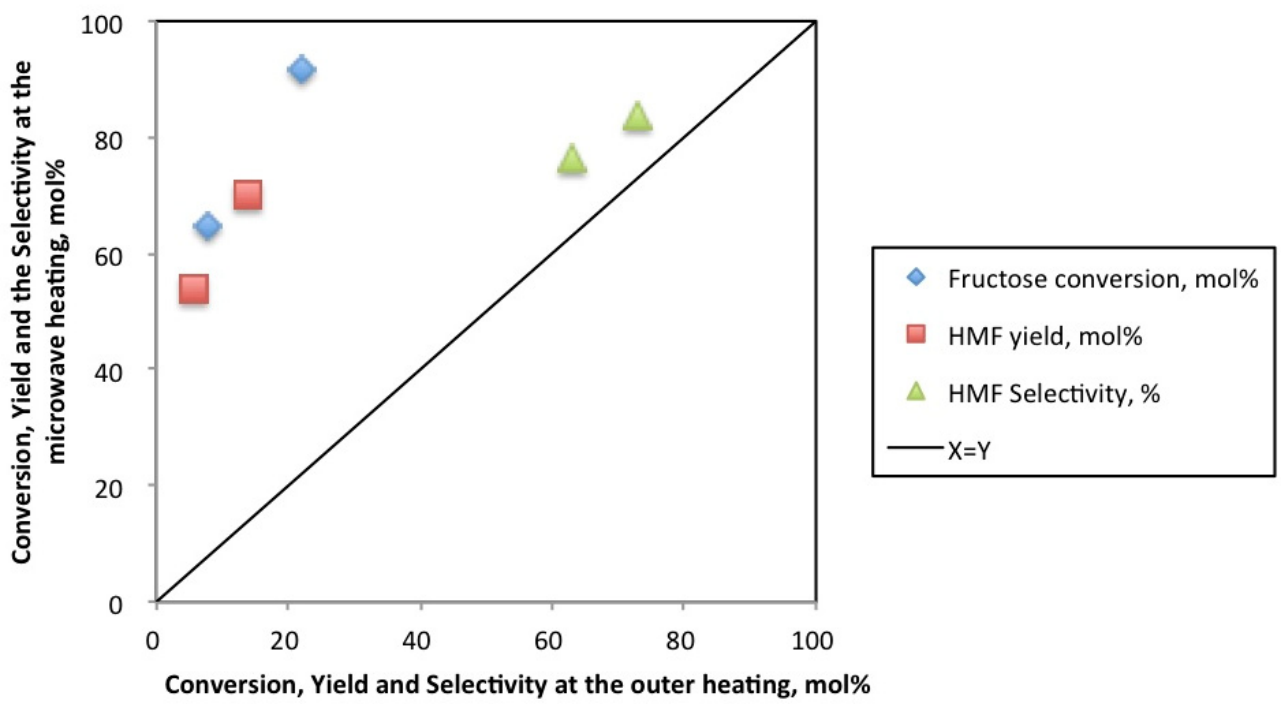

Figure 6. Parity plot of the fructose conversion in acetone-water mixture: comparison of fructose conversion, HMF yield and HMF selectivity between the outer heating and the microwave heating

\subsection{Partial oxidation of glycerol into formic acid at hydrothermal condition ${ }^{[16]}$}

Figure 7 shows the experimental results of partial oxidation of glycerol in hydrothermal condition $^{[16]}$. The reaction condition was 0.5 of ER, $200{ }^{\circ} \mathrm{C}$ of reaction temperature, $10 \mathrm{~min}$ of reaction time. Here, ER is equivalent ratio of oxygen and is defined as below:

$$
E R[-]=\frac{\text { Loaded amount of oxygen atom }[\mathrm{mol}]}{\text { Required amount of oxygen atom for complete oxidation }[\mathrm{mol}]}
$$

1 mole of glycerol $\left(\mathrm{C}_{3} \mathrm{H}_{8} \mathrm{O}_{3}\right)$ was completely oxidized by $7 / 2$ moles of $\mathrm{O}_{2}$ into 3 moles of $\mathrm{CO}_{2}$ and 4 moles of $\mathrm{H}_{2} \mathrm{O}$. 1 mole of hydrogen peroxide is decomposed into 1 mole of $\mathrm{H}_{2} \mathrm{O}$ and $1 / 2$ moles of $\mathrm{O}_{2}$ and so the ratio of glycerol to hydrogen peroxide in the batch type reactor (high pressure glass reactor for the microwave heating and stainless steel reactor for the outer heating) was 1:3.5. Here we focused on formic acid formation from glycerol because formic acid was expected as a sustainable hydrogen storage resource because it can easily decompose into hydrogen when needed ${ }^{[16]}$.

As shown in Figure 7, glycerol conversion and formic acid yield obtained by the microwave heating was a little higher than those by the outer heating. For the selectivity of formic acid formation, the microwave heating also enhanced. 


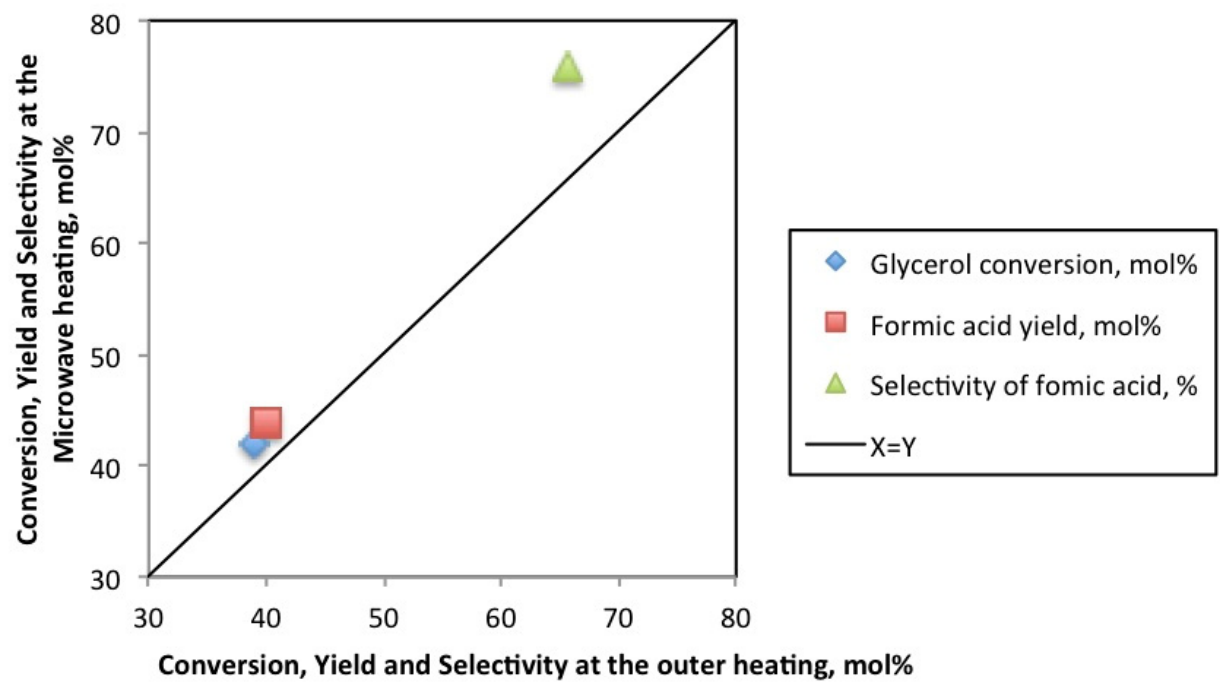

Figure 7. Parity plot of the glycerol partial oxidation: comparison of heating method for glycerol partial oxidation $\left(200{ }^{\circ} \mathrm{C}, 10 \mathrm{~min}, \mathrm{ER}=\right.$ (oxygen atom in the reactor)/(oxygen molecular atom for complete oxidation $)=0.5)$

\subsection{Glucose conversion into $\mathrm{HMF}$ in[Bmim] $[\mathrm{Cl}]^{[17]}$}

In ionic liquid, 1-methyl-3-butyl imidazolium chloride,[Bmim][Cl], glucose conversion into $\mathrm{HMF}$ in the presence of $\mathrm{CrCl}_{3}$ was carried out with outer heating (oil bath heating) and microwave heating at identical conditions for two temperatures, shown in Table 3. To compare the differences between the outer heating and the microwave heating, the experimental data are plotted in Figure 8 as parity plot. It was apparently seen that both glucose conversion and the reaction pathway to HMF formations were promoted some degrees by microwave irradiation.

\begin{tabular}{cccccc}
\hline & $\begin{array}{c}\text { Reaction } \\
\text { temperature, }{ }^{\circ} \mathrm{C}\end{array}$ & $\begin{array}{c}\text { Reaction } \\
\text { time, min }\end{array}$ & $\begin{array}{c}\text { Glucose } \\
\text { conversion,m } \\
\text { ol\% }\end{array}$ & $\begin{array}{c}\text { HMF yield, } \\
\text { mol\% } \%\end{array}$ & $\begin{array}{c}\text { HMF } \\
\text { selectivity, \% }\end{array}$ \\
\hline Outer heating & 120 & 5 & 63 & 45 & 71.4 \\
\hline $\begin{array}{c}\text { Microwave } \\
\text { heating }\end{array}$ & 140 & 0.5 & 68 & 48 & 70.6 \\
\hline
\end{tabular}

Condition: $1 \mathrm{~g}$ of $1 \mathrm{wt} \%$ of glucose in[Bmim] [Cl], $0.015 \mathrm{~g} \mathrm{CrCl}_{3} \bullet 6 \mathrm{H}_{2} \mathrm{O}$

Table 3. Comparison of glucose conversion between the outer heating and microwave heating[18] 


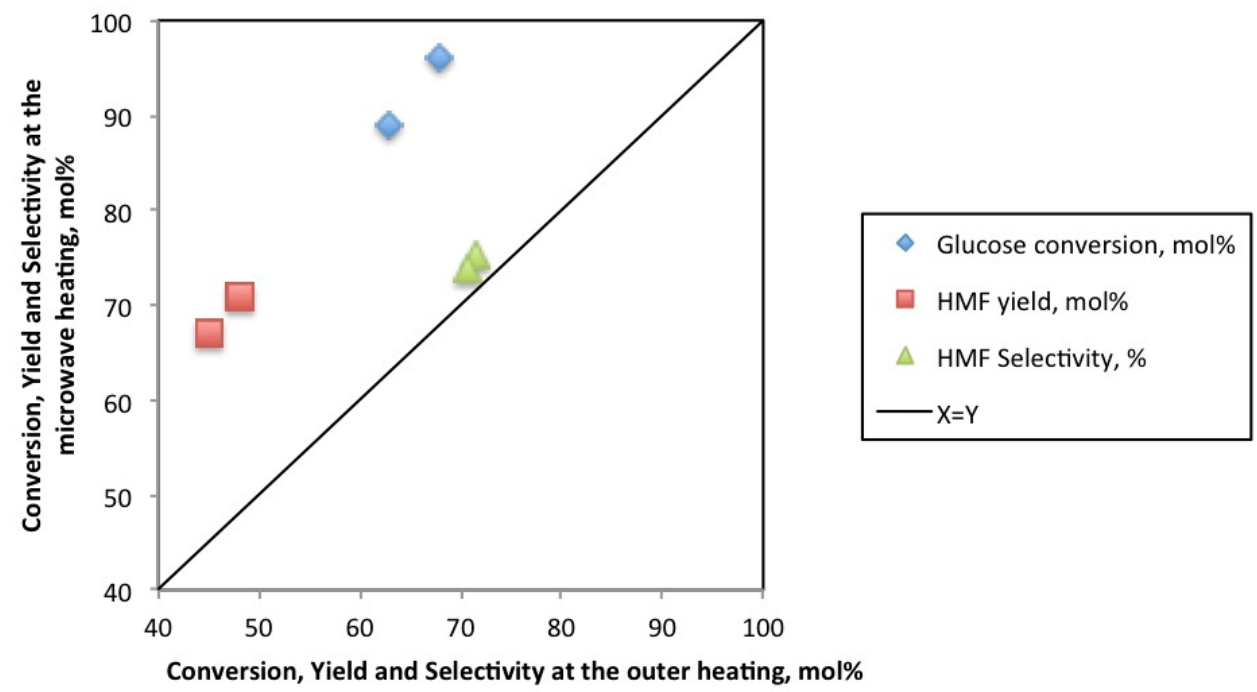

Figure 8. Parity plot of the glucose conversion: comparison of glucose conversion, HMF yield and HMF selectivity between the outer heating and the microwave heating

\subsection{Effect of microwave heating on the biomass conversions}

As introduced the above sections, the enhancement of reaction rate and some degrees of change of reaction pathway were seen for glucose, glycerol and fructose conversion in water and ionic liquid system. Microwave effect has been considered as thermal and/or specific effect.

Lidstroem et al. reviewed microwave-assisted organic syntheis ${ }^{[18]}$. In their review, they mentioned that some organic reactions were speeded up by microwave heating and the enhancement of the chemical reactions was mainly resulted in the difference of temperature between conductive heating (heat transferred from outer heating source) and inner heating (heat is directly supplied by microwave heating). Conventionally, a typical organic synthesis is conducted with glassware and heat transfer from outer heater to a reaction fluid in the glass is slow. On the other hand, microwave heating is capable of rapid heating because of direct energy supply to the reaction fluid. Also, microwave is sometimes absorbed heterogeneously in a reaction vessel and hot spot (regionally higher temperature place exist in the reaction system) is probably encountered. The difference of temperature profile and/or the existence of the hot spot would affect chemical reactions 
and the researcher considered that microwave has some specific effect on some reactions. At the experimental studies described in this chapter, the heating profiles and the final temperature for both the reactions by the outer heating and the microwave heating were tried to be identical and thus the effect of the achieved temperature and the heating rate on the reaction could be excluded from the reason of the difference of the biomass conversions. For the viewpoint of hot spot, it is difficult to know whether hot spot exit or not, however the explanation of the reason why the reaction behavior was changed by the microwave heating is difficult. At all of the biomass conversion introduced in this chapter, selectivity of the product was also enhanced and it means that microwave selectively enhanced a specific reaction pathway. This promotion of specific reaction can not be explained from the thermal effect.

It has been known that some difficult-to-rationalize effects (which are referred as specific or nonthermal effects) were seen in some organic reactions ${ }^{[6]}$. In general, specific effect of microwave has been proposed to be the result of a direct interaction of dipoles in an electric field with a specific functional group in the reaction medium. It has been argued that there is a decrease in activation energy ${ }^{1[9]}$ or an increase in the pre-exponential factor in the Arrhenius law due to enhanced orientation effects of polar species in an electromagnetic field that lower steric hindrances ${ }^{[5,20]}$. Some researchers have proposed that the effective collision among reactant molecules under microwave irradiation is enhanced and result in the pre-exponential factor in the Arrhenius law increases ${ }^{[5]}$. Furthermore, a similar effect should be observed for chemical reaction between reactants containing polar groups, where the rotation of polar species increases and the molecules effectively leads to activation (from ground state to transition state) under the microwave irradiation, thus enhance the reactivity by lowering the activation energy ${ }^{[5]}$. Bren et al. ${ }^{[21]}$ proposed a novel physical mechanism for microwave catalysis based on rotationally excited reactive species and verify its validity through a computer simulation of a realistic chemical reaction. They thought that the rotation rate of polar molecules are enhanced under the microwave irradiation, this gives a higher rotational temperature than the translational temperature. The activation free energy is reduced when the rotational temperature is higher than the translational temperature, which constitutes a catalytic effect. These specific effects of microwave heating on organic reactions including thermal effect like hot spot and molecule-level phenomenon and it is difficult to be clarified experimentally. To reveal the effect of "specific effect" of microwave irradiation molecular level studies such as quantum chemical calculations is strongly required.

\subsection{In-situ observation of cellulose hydrolysis in ionic liquid}

Finally, in this section, we describe usefulness of the microwave setup developed by us for in-situ observation. Here, cellulose hydrolysis in ionic liquid ([Bmim] [Cl]) is picked up. Figure 9 shows effect of loading amount of reaction fluid ( $5 \mathrm{wt} \%$ cellulose ionic liquid solution) in the high pressure glass reactor (4 in Figure 1) on cellulose hydrolysis. When 
cellulose hydrolysis progresses stoichiometrically, $3.1 \times 10^{-4}$ mole (which is equal to glucose unit in $0.05 \mathrm{~g}$ of cellulose) of water is required in the cease of $1 \mathrm{~g}$ of the amount of the solution. The water content in the solution in $[\mathrm{Bmim}][\mathrm{Cl}]$ that was used in this study was $0.8 \mathrm{wt} \%\left(4.4 \times 10^{-4}\right.$ mole $)$ and it was enough amount for cellulose hydrolysis. Reaction temperature was $120{ }^{\circ} \mathrm{C}$ and reaction time was $20 \mathrm{~min}$. To keep water liquid phase, 1.2 $\mathrm{MPa}$ of inert gas was loaded before heating up to $120{ }^{\circ} \mathrm{C}$. Catalyst was Amberlyst- 15 and its amount was equal to the loaded amount of cellulose (thus when $1 \mathrm{~g}$ of the solution was loaded in the reactor, $0.05 \mathrm{~g}$ of Amberlyst-15 was loaded). As shown in this figure, with increasing the amount of the solution, glucose yield gradually decreased. More than $3 \mathrm{~g}$ of the solution in the reactor, glucose yield changed unsteadily with increasing the amount of the solution. Figure 10 shows in-situ observation of cellulose hydrolysis when $3 \mathrm{~g}$ of the solution was loaded. As shown in Figure 10, ionic liquid ([Bmim][Cl]), cellulose, and water were miscible at first (Figure 10-1). With progressing hydrolysis of cellulose, phase separation was observed (Figure 10-2). Further progression of the reaction, water-rich phase (upper phase in the reactor) was completely separated from ionic liquid-rich phase (lower phase) and cellulose layer was also observed between the upper and lower phase (Figure 10-3).

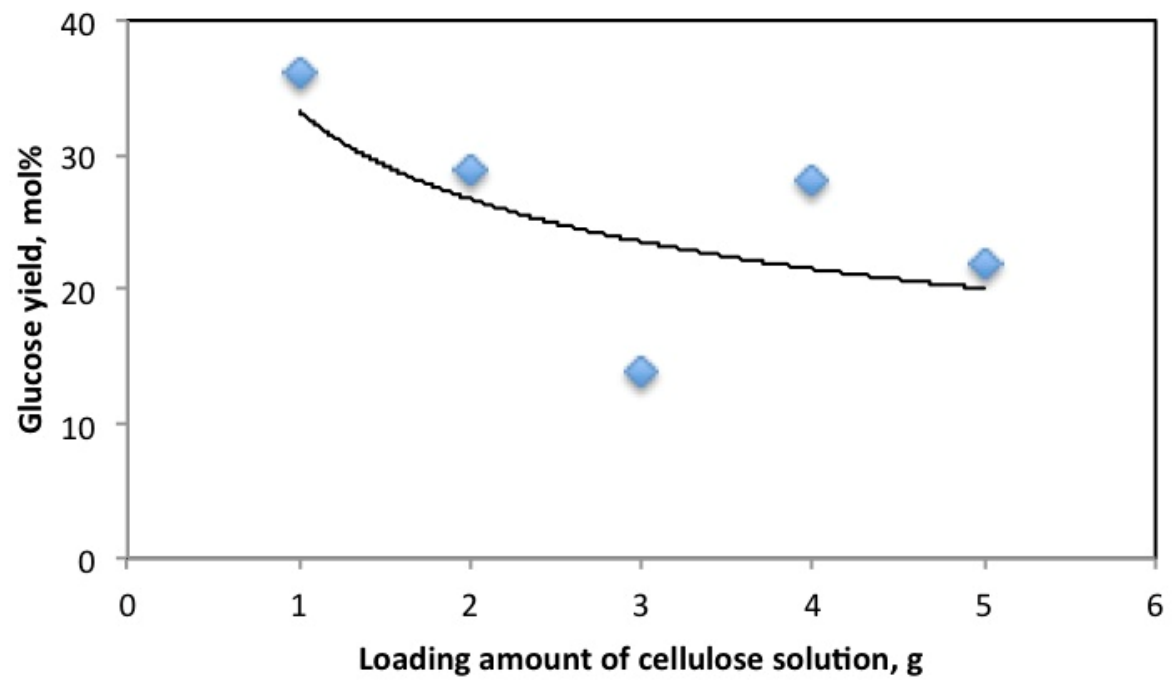

Condition: $5 \mathrm{wt} \%$ of cellulose, Cellulose/Amberlyst $=1,120{ }^{\circ} \mathrm{C}, 20 \mathrm{~min}$

Figure 9. Effect of loading amount of cellulose solution on glucose yield from cellulose hydrolysis in $[\mathrm{Bmim}][\mathrm{Cl}]$ in the presence of Amberlyst-15 


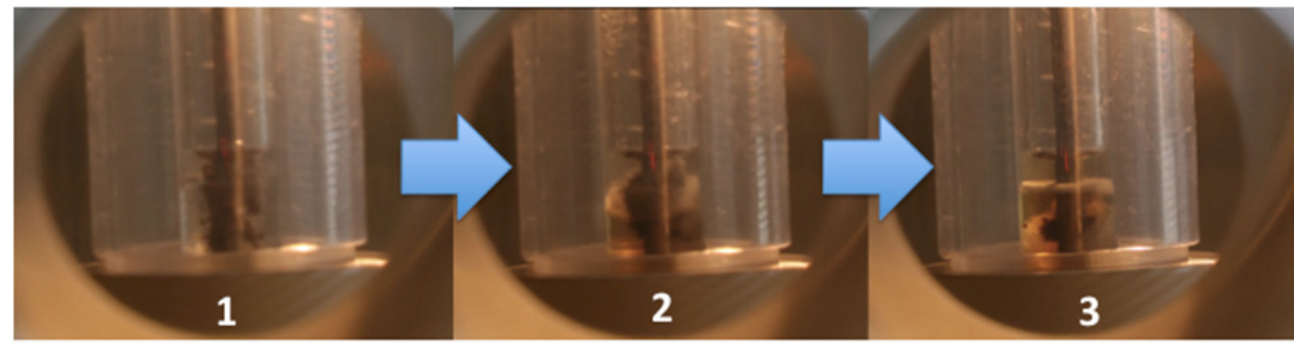

1. Ionic liquid, cellulose, and water were firstly miscible.

2. With progressing hydrolysis of cellulose, phase separation was observed.

3. Water-rich phase was completely separated from ionic liquid-rich phase and cellulose layer was also observed.

Figure 10. In-situ observation of cellulose hydrolysis in ionic liquid and water mixture.

Viscosity of ionic liquid is high, particularly when ionic liquid contains cellulose and the viscosity of the ionic liquid solution is much higher than pure ionic liquid. During the hydrolysis, the viscosity of the reaction fluid gradually decreases with increasing product (mainly glucose) yield. When stirring in the reactor was insufficiency, viscosity and density of the solution was disproportionate. In addition, the solid catalyst was used and it was aggregated when the viscosity (and density) was heterogeneously distributed. The phase boundary formed with unreacted cellulose prohibited mass transfer and the disproportion of the solution was accelerated. Surely, although there are several reasons for explaining the reaction behavior shown in Figure 9, the effect of mass transfer (also phase behavior) has to be the main factor for reducing glucose yield.

In this chapter, we only introduce one example for effectiveness of in-situ observation but insitu observation definitely provides a useful hint for considering kinetics of many reactions. Our microwave system employs both microwave- and visible light-transparent material for high pressure reactor and whole the reactor can be observed during the reaction.

\section{Conclusion}

A novel high pressure reactor was introduced in this chapter. The apparatus allows kinetic study because of rapid heating and rapid cooling. Also in-situ observation inside a reactor during reaction is possible.

Here, dehydration of fructose into hydroxymethyl furfral (it is a chemical block made from lignocellulose material for biomass refinery), glycerol into formic acid, and glucose 
into HMF were mentioned. All of the reactions were affected by microwave irradiation. Through the experimental results, we tried to discuss the effect of microwave irradiation.

The usefulness of in-situ observation for cellulose hydrolysis in[Bmim][Cl] was shown. During the reaction, phase was changed from homogeneous into heterogeneous and it was considered that the phase change mainly resulted in inhibition of cellulose hydrolysis.

\section{Author details}

Masaru Watanabe, Taku M. Aida and Richard Lee Smith, Jr.

Tohoku University, Japan

Xinhua Qi,

Nankai University, China

\section{References}

[1] R. Gedye, F. Smith, K. Westaway, H. Ali, L. Baldisera, L. Laberge, J. Rousell, Tetrahedron Lett. 27 (1986) 279.

[2] R.J. Giguere, T.L. Bray, S.M. Duncan, G. Majetich, Tetrahedron Lett. 27 (1986) 4945.

[3] M.J. Gronnow, R.J. White, J.H. Clark, D.J. Macquarrie, Org. Process. Res. Dev. 9 (2005) 516.

[4] D. Dallinger, C.O. Kappe, Chem. Rev. 107 (2007)

[5] M. Hosseini, N. Stiasni, V. Barbieri, C.O. Kappe, J. Org. Chem. 72 (2007) 1417.

[6] C.O. Kappe, Angew. Chem. Int. Edit. 43 (2004) 6250.

[7] M. Kremsner, A. Stadler, C.O. Kappe, Microwave Meth. Organ. Synth. 266 (2006) 233.

[8] E. Comer, M.G. Organ, J. Am. Chem. Soc. 127 (2005) 8160.

[9] G. Shore, S. Morin, M.G. Organ, Angew. Chem. Int. Edit. 45 (2006) 2761.

[10] C. Limousin, J. Cleophax, A. Petit, A. Loupy, G. Lukacs, J. Carbohydr. Chem. 16 (1997) 327.

[11] A. Orozco, M. Ahmad, D. Rooney, G. Walker, Process. Saf. Environ. 85 (2007) 446.

[12] A.M. Sarotti, R.A. Spanevello, A.G. Suarez, Green Chem. 9 (2007) 1137.

[13] M.M. Andrade, M.T. Barros, P. Rodrigues, Eur. J. Org. Chem. (2007) 3655.

[14] X. Qi, M. Watanabe, T. M. Aida, R. L. Smith, Jr., Catal. Commun. 9 (2008) 2244

[15] X. Qi, M. Watanabe, Taku M. Aida, R. L. Smith, Jr., Green Chem., 10 (2008) 799.

[16] M. Watanabe, T. M. Aida, R. L. Smith Jr., H. Inomata, J. Jpn. Petrol. Inst., submitted.

[17] X. Qi, M. Watanabe, T. M. Aida, R. L. Smith, Jr., ChemSusChem 3 (2010) 3.

[18] P. Lidstroem, J. Tierney, B. Wathey, J. Westman, Tetrahedron, 57 (2001) 9225.

[19] F. Joo, ChemSusChem 1 (2008) 805. 
178 The Development and Application of Microwave Heating

[20] C.O. Kappe, A. Stadler, Microwaves in Organic and Medicinal Chemistry, Wiley-VCH, Weinheim, Germany, 2005.

[21] U. Bren, A. Krzan, J. Mavri, J. Phys. Chem. A 112 (2008) 166. 